\title{
Arsa karşılığı inşaat işlerinin muhasebeleştirilmesi
}

\author{
aSMMM Cafer ŞUEKINCi
}

a Sakarya Üniversitesi İşletme Ensitüsü Doktora Öğrencisi, cafer.suekinci@ogr.sakarya.edu.tr ORCID: 0000-0002-1659-5593

\section{MAKALE BILGILERi}

Araştırma Makalesi Geliş Tarihi 8 Nisan 2020

Revizyon 30 Eylül 2020

Kabul tarihi 10 Ekim 2020

\section{Özet}

Inşaat sektörü, ülkemizin en dikkat çeken ve yakından takip edilen sektörlerinden biridir. İki ana faaliyet alanına ayrılmaktadır. Birincisi özel inşaat faaliyeti ikincisi de taahhüt şeklinde yapılan inşaat faaliyetidir. Aynı zamanda yapısı itibariyle uzun dönemler süren inşaat faaliyeti içerisinde bir çok özellikli durum barındırmaktadır. Çalışmada özel inşaat faaliyeti içerisinde uygulamada sıklıkla karşılaşılan ve aynı zamanda muhasebeleştirilmesi konusunda tereddütler bulunan arsa karşılığı inşaat faaliyeti açıklanmaya çalışılmıştır.

Anahtar Kelimeler: İnşaat, Özel İnşaat, Muhasebe

Jel Kodları: L74, M41

\section{The accounting of flat for land basis construction activities}

\section{Abstract}

Stereotype threat refers to a psychological experience that is associated with the fear of being evaluated by a negative stereotype about one's social group/identity (religion, language, race, gender, political opinion, etc.). In this article, the qualitative research method is preferred and in-depth interviews are conducted with the participants to determine their emotional/behavioral responses to stereotype threat in the workplace. The results of the interviews revealed some strategies that employees employed against stereotype threats that are classified as; (a) Fending off the stereotype, (b) Discouraged by the stereotype, and (c) Resilient to the stereotype. It is also believed that this study will contribute to the national literature as it is the first study that has been conducted with a qualitative method on the stereotype threat and will shed further light on future research on this topic.

Key Words: Construction, Special Constructions, Accounting

Jel Kodları: L74, M41

\section{Gíriş}

Arsa karşılığı inşaat faaliyeti müteahhitlerin, arsa satın alınması için yeterli finansmana sahip olmamalarından ve başkalarının arsaları üzerinde inşaat yaparak daha fazla konut üretmelerini sağladığı için müteahhit firmaların tercih ettiği bir inşaat yapım yöntemidir.

Arsa sahipleri bu yöntemi tercih etme nedenleri; arsalarının mevcut durumundan daha iyi bir değere kavuşmasını sağlamak istemeleri, kendi ekonomik güçleri ile arsalarının üzerine yeni bina yapma imkanlarının olmayışı ya da profesyonel bir firmanın inşaatı yapmasını istemeleridir. Arsa karşılığı inşaat faaliyeti içerisinde arsa sahibi ve müteahhit açısından bir takım vergisel yükümlülükler doğmaktadır.

Bu konuda hem yargının hem de idarenin konuya bakışları farklılık arz etmektedir. Dolayısıyla bu da vergisel açıdan bir takım sorunları beraberinde getirmektedir. (Çatıkkaş\&Şuekinci,2012:171) Kanun bazında net düzenlemeler olmadığı için Danıştay yerleşik içtihatlarında arsa karşılığı inşaat işlerini servetin şekil değiştirmesi kendine özgü (sui generis) bir olay görmekte Gelir İdaresi ise arsa sahipleri ile müteahhitler arasındaki ilişkiyi trampa olarak değerlendirmektedir. Dolayısıyla Gelir İdaresi nezdinde arsa sahipleri ile müteahhitler arasındaki ilişki hem KDV'ye tabi hem de Gelir Vergisi hükümlerine tabidir. Çalışmada arsa karşılığı inşaat işlerinin vergisel özellikli durumları ile birlikte özellikle uygulamada sorun teşkil eden arsa sahiplerine fatura düzenlenmesi ve muhasebeleştirilmesi konusu detaylı bir şekilde ele alınmıştır.

\section{INŞAAT FAALIYETi ÇEŞiTLERi}

Inşaat faaliyetleri iki ana başlıkta toplanmaktadır. Özel inşaat faaliyeti ve taahhüt şeklinde yapılan inşaat faaliyetleridir. Aşağıdaki tablodan da görüleceği üzere inşaat faaliyetinin birçok alt faaliyet alanı bulunmaktadır. İnşaat faaliyetinin hangi sınıflandırmaya tabi olduğunun tespiti muhasebe ve vergi açısından çok önemlidir. Çünkü; taahhüt işlerinde işi yapan taşeron firmanın yapılan işten pay alma ya da diğer bir deyişle mülkiyet hakkı yoktur. Taahhüt işlerinde hizmet söz konusudur. Ayrıca 193 sayılı Gelir Vergisi Kanununda da taahhüt işlerinin yıllara yaygın olması durumunda özel bir vergilendirme söz konusudur. 193 sayılı Gelir Vergisi Kanunu 42.maddesinde yapılan taahhüt işinin hesap dönemini aşması durumunda yıllara yaygın inşaat olarak tarif edilmektedir. Yıllara yaygın inşaat işi olarak sınıflandırıldığında stopaj kesintisi, KDV tevkifatı, kar veya zararın ertelenmesi gibi özel durumlar bulunmaktadır.

Dolayısıyla taahhüt işlerini ilgilendiren bir işin özel inşaat olarak değerlendirilip muhasebe kayıtlarının hatalı yapılması, taahhüt işlerine özgü vergisel hükümlerin gözden kaçması durumunda telafi edilemeyecek sonuçlar ortaya çıkacağı gibi işin devam ettiği yıllardaki tüm finansal tablolar da hatalı olacaktır. İnşaat muhasebesindeki en temel konu, yapılan inşaat faaliyetinin hangi tür inşaat olduğunun doğru tespit edilmesidir. Güvenilir, gerçeğe uygun bir raporlama için faaliyetin hangi inşaat işini ilgilendirdiğinin tespiti önemlidir.

Tablo 1. Inşaat faaliyet çeşitleri

\begin{tabular}{|c|c|}
\hline TAAHHÜT ŞEKLINDE YAPILAN INŞAAT IŞLERi & ÖZEL INSSAAT FAALIYETLERi \\
\hline $\begin{array}{l}\text { 1.Yurt İçi İnşaat Taahhüt İşleri } \\
\text { (Yıllara Yaygın Ve Yıllara Yaygın Olmayan İnşaat Taahhüt } \\
\text { İşleri) }\end{array}$ & 1.Arsa Karşılığı İnşaat İşleri \\
\hline \multirow[t]{5}{*}{ 2.Yurt Dışı İnşaat İşleri } & 2.Yapıp Kullanmak Amaçlı İnşaat İşleri \\
\hline & 3.Satış Amaçlı İnşaat İşleri \\
\hline & 4. Hasılat Paylaşımlı İnşaat İşleri \\
\hline & 5.Yatırım Amaçlı İnşaat İşleri \\
\hline & 6.Yapı Kooperatiflerinin Faaliyetleri \\
\hline
\end{tabular}




\subsection{TAAHHÜT ŞEKLINDE YAPILAN INŞAAT FAALIYETLERI}

Taahhüt şeklinde yapılan inşaat işleri en temel özelliği ya da diğer inşaat işlerinden farklı olduğu nokta mülkiyet konusudur. Taahhüt işletmeleri yapılan inşaat işinin belli bir bölümünün yapımı için hizmet vermektedir. Taahhüt şeklinde inşaat işi yapanlar, işveren ile yapılacak iş konusunda mutabık kaldıktan sonra işverenin taşeronu konumunda olup sadece anlaşma yapılan işin hizmetini vermektedir. Dolayısıyla taahhüt işlerinde hizmet işlerinde olduğu gibi tüm maliyetler 740 Hizmet Üretim Maliyeti hesabında takip edilmektedir.

193 sayılı Gelir Vergisi Kanunu 42. Maddesinde "Birden fazla takvim yılına sirayet eden inşaat ve onarım işlerinden kar veya zarar işin bittiği yıl kati olarak tespit edilir ve tamamı o yılın geliri sayılarak, işin bittiği yıl beyannamesinde gösterilir." Burada üç unsurun tespit edilmesi gerekmektedir. Birincisi yapılan iş inşaat işi olmalı, ikincisi taahhüt olmalı ve üçüncüsü de iş hesap dönemini aşmalıdır. Bu üç kriterinde gerçekleşmesi durumunda işin bittiği geçici kabul tutanağının düzenlendiği yıla kadar taahhüt işletmeleri fatura düzenler ancak fatura bedeli gelir hesaplarına değil bilançonun pasifinde 350 Yıllara Yaygın Hakediş bedelleri hesabında takip edilir. Aynı şekilde maliyetler de 170 Yıllara Yaygın İnşaat Onarım Maliyetleri hesabında takip edilmektedir.

Bu doğrultuda, iş kaç yıl sürerse sürsün, işin devam ettiği yıllarda taahhüt işleri yapan bir firmanın ilgili dönemlerdeki kar veya zarar tablosu incelendiğinde ne hasılat ne de inşaat giderlerine ilişkin tutarların yansıtılmadığı anlaşılmaktadır. İ̧̧ bitene kadar (geçici kabule kadar) gelir tablosunda hasılatın raporlanması söz konusu olmamaktadır. (Örten, Kaval \&Karapınar;2015: 126) iş bittiğinde birden fazla yıl devam eden bir işin hasılatının tek bir yılda elde edilmiş gibi raporlandığı görülmektedir. (Çatıkkaş, Esen \& Şuekinci, 2018:193) Ancak bu durumda birden fazla yıl süren işlerde işletmenin başka da faaliyeti bulunmuyorsa gelir ve brüt kar sıfır olacaktır.

Literatürde bu yöntem tamamlanmış sözleşme yöntemi olarak adlandırılmaktadır. Türkiye Finansal Raporlama Standartları 15'nolu Müşteri Sözleşmelerinden Hasılat Standardında Girdi yöntemi, Büyük Boy İşletmeler İçin Finansal Raporlama Standardında ise Tamamlanma Yüzdesi Yöntemi kullanılmaktadır. Her iki yöntemde de her yıl işin ne kadarı tamamlandıysa tamamlanma yüzdesi tespitinin yapılması ve tamamlanma yüzdesine göre de tamamlanma oranına bağlı olarak hasılatın raporlanması sağlanmaktadır. Dolayısıyla taahhüt işletmesinin faaliyeti ölçüsünde finansal tablolarına da doğru hasılat tutarının yansıtılması sağlanmış olmaktadır.

\section{2 ÖZEL INŞAAT FAALIYETLERI}

Özel inşaat işinde yapılan işten işi yapanın bir mülkiyet hakkı söz konusudur. (Çatıkkaş ve Şuekinci,2013:25) Dolayısılla işi yapan müteahhit firma arsanın sahibi olabilir yada arsa sahibi ile arsa karşılı̆ı anlaşma yapması mümkündür. Uygulamada birçok özel inşaat faaliyeti olmasına karşın en yaygın olarak karşımıza çıkan arsa karşılı̆ıı inşaat işleridir. Arsa sahibi ile müteahhidin aynı olması durumunda kullanım amaçlı ya da yapıp satmak amaçlı inşaat faaliyeti gerçekleşebilir.

\subsection{TAAHHÜT ŞEKLINDE YAPILAN INŞAATLAR ILE ÖZEL INSŞAAT FAALIYETLERI ARASINDAKi FARKLAR}

Özel İnşaat; inşaat faaliyeti içerisinde iki ana başlıktan bir tanesidir. Özel inşaat'ta temel unsur arsadan ve inşaat yapımı sonucu oluşacak yapıdan işi yapanın da hak sahibi olmasıdır. Taahhüt şeklinde yapılan inşaatlardan farklıı̆ıı da burada ortaya çıkmaktadır. Taahhüt şeklinde yapılan inşaatlar hizmet işidir. İşin mülkiyeti işi yapana ait değildir (Çatıkkaş ve Şuekinci,2016:2)

Başkaları nam ve hesabına inşaat yapanlar hizmet işletmesi olarak nitelendirilirler. Hizmet işletmelerinin inşaat faaliyeti sonucu ortaya çıkardıkları ürün üzerinde herhangi bir tasarruf hakları yoktur. Ürün işi yaptırana aittir. (Selimoğlu,2013:381)

Bu tür inşaatlarda taraflar; işin sahibi bir gerçek veya tüzel kişi ile yüklenici firmadır. İşin sözleşme koşullarına uygun olarak yüklenici firma tarafından, belli bir ücret karşılı̆̆ı yapılması ve teslim edilmesi taahhüt şeklinde yapılan inşaat ve onarma işidir. Yüklenici işin sahibine bir ücret karşıllğında sözleşme koşullarına uygun olarak taahhüt etmiş olduğu işi yani hizmeti yerine getirmektedir. Bu yönüyle taahhüt şeklinde yapılan inşaat faaliyetlerinde yüklenicinin yapmış olduğu iş hizmet işidir. Yapılan iş imalat olmakla birlikte yapılan imalat sipariş üzerine imalattır ve arsanın mülkiyeti imalatı yapana değil siparişi verene aittir. (Çatıkkaş ve Şuekinci, 2016:172)

Bu nedenle muhasebe kayıtlarında da farklııklar söz konusudur. Özel İnşaat işlerinin muhasebeleştirilmesinde üretim faaliyeti olduğu için muhasebeleştirilirken ve maliyet takibi yapılırken ilk madde malzeme, direkt iş̧̧ilik giderleri ve genel üretim giderleri hesapları kullanılır. Ancak taahhüt işlerinde hizmet üretim söz konusu olduğundan “Hizmet Üretim Maliyeti” hesabında gerçekleşen maliyetler takip edilir.

Taahhüt şeklinde yapılan inşaatlarda Uluslararası Finansal raporlama standartları ile ülkemiz vergi uygulamaları arasında farklılıklar bulunmaktadır. Standartlarda tamamlanma yüzdesi yöntemi kullanıımaktadır. Vergi uygulamalarında ise tamamlanmış sözleşme yöntemi kullanılarak iş bitene kadar işin devam ettiği yıllarda gelir tablosuna herhangi bir gelir unsuru yansıtılmamaktadır. Tamamlanmıs sözleşme yöntemi ile tamamlanma yüzdesi yöntemi karşılaştııılı̆̆ında, tamamlanma yüzdesi yönteminin dönemsellik ilkesi ile daha iyi uyum sağladığı görülmektedir. (Demir,2015:840)

Yıllara yaygın inşaat ve onarım işi yapan mükellefler, işin devam ettiği yıllarda elde ettikleri hasılat ve yaptıkları giderleri ilgili dönem bilançonun aktifinde Yıllara Yaygın İnşaat Onarım Maliyetleri hesabı ve bilançonun pasifinde Yıllara Yaygın Hakediş Bedeli hesapları ile izleyen yıllara aktaracak; işin bittiğ̈i ve geçici kabulün yapıldığı yılda da kar veya zararı kesin olarak tespit edip tamamını o yılın geliri veya zararı olarak beyan edeceklerdir. (Yereli ve Diğerleri, 2011:117)

\section{ARSA KARŞILIĞI INŞAAT FAALIYETi}

Müteahhitler ile arsa sahiplerinin farklı kişiler olduğu bir alt faaliyet türüdür. Müteahhitlerin artan konut intiyacını karşılamak maksadıyla arsa ve inşaatı bir arada yapmak için yeterli finansmana sahip olmadıkları veya arsa sahiplerinin de inşaat faaliyetini yapacak yeterli teknik bilgi ve finansmana sahip olmamalarından dolayı kat karşılığı inşaat faaliyeti oluşmuştur. Uygulamada arsanın konumuna ve değerine göre değişen oranlarda anlaşmalar yapıılığı görülmektedir. Kat karşlığı inşaat işleri aslında özü itibariyle bir takas işlemidir. Çünkü; müteahhitler arsa sahiplerine aldıkları arsadan aldıkları pay için arsa sahiplerine yeni yapılacak eserden anlaşılan oran dahilinde pay vermektedirler. Arsa sahipleri de yeni yapılacak eserden alacakları pay karşılığında müteahhitlere arsadan pay vermektedirler. Yapılan işlem ticari bir işlemdir. Ancak bedeli gayri nakdi bedel karşılığında ödenmektedir.

Örneğin: Efe Bey İstanbul Üsküdar'da sahibi olduğu arsayı \%40 oran ile müteahhide vermeyi planlamaktadır. Ortaya çıkacak yeni binada 10 daire çıkacağı yapılan çalışmalar sonucu tespit edilmiştir. Bu bina da toplamda yapılacak olan 10 dairenin 6 dairesi arsa sahiplerine 4 dairesi müteahhide kalacaktır. Müteahhit binayı tamamladığında arsa sahibine kendisine kalan 4 dairenin arsa payı için nakdi bir bedel ödememektedir. Ancak arsa sahibine kalan 6 daireyi teslim etmektedir. Aldığı 4 dairenin arsa payına karşılık 6 dairenin inşa edilip teslim edilmesi takas işlemidir.

Yukarıdaki örnekte de bahsettiğimiz gibi arsa karşlığı inşaat işlerinde takas(trampa) söz konusudur. Ancak kanun bazında net bir düzenleme söz konusu olmadığı için yargı kararlarında müteahhit ve arsa sahipleri arasındaki ilişki servetin şekil değiştirmesi olarak kabul edilmektedir. Bu da Vergi Usul kanununa göre yapılan işlemlerde tereddütlere neden olmaktadır.

60 nolu KDV sirkülerinde arsa karşlığı işlerde vergiyi doğuran olayın tarifi şu şekilde yapılmıştır. "Arsa karşılığı inşaat işlerinde vergiyi doğuran olay, müteahhidin arsa karşılığı konut, işyeri gibi bağımsız birimleri arsa sahibine teslimiyle gerçekleşmektedir. Bu tarih itibariyle arsa açısından da vergiyi doğuran olay vuku bulmaktadır. Taşınmazda teslim kural olarak tapuya tescil ile gerçekleşmekle birlikte, tapuya tescilden önce bağımsız birimlerin alııının tasarrufuna terk edilmesi durumunda da vergiyi doğuran olay gerçekleşmektedir."

Arsa sahibinin dairelerini satışından elde ettiği kazancın ticari kazanç mı yoksa değer artış kazancı mı olduğunun tespiti önemlidir. Gelir Vergisi Kanunun 37/4.maddesi gereği gayrimenkullerin alım satım ve inşa işleri ile devamlı uğraşanların elde ettiği kazanç ticari kazanç olarak kabul edilmiştir. Önemli olan husus işin devamlılı̆ı̆ıır. (Özcan,2011:112)

Danıştay'ın yaklaşımında olduğu gibi, idare de faaliyetin devamlılık niyeti ile yapıldığını belirleyen objektif ölçünün, muamelenin çokluğu olduğu görüşündedir. Muamelenin çokluğundan kasıt aynı takvim yııında birden fazla veya birbirini takip eden yıllarda art arda satılmasıdır. (Türüt,2009:210)

KDV Uygulama Genel Tebliğine göre arsa karşıllğı inşaat iş̧lerinde vergiyi doğuran olay, "müteahhidin arsa karşıı̆ı̆ı konut, işyeri gibi bağımsız birimleri arsa sahibine teslimiyle gerçekleşir. Arsanın bir iktisadi işletmeye dâhil olması veya arsa sahibinin arsa alım satımını mutad ve sürekli bir faaliyet olarak sürdürmesi durumunda, vergiyi doğuran olayın vuku bulduğu tarihte, müteahhide yapılan bu arsa teslimi nedeniyle düzenlenecek faturada arsa karşılığı 
alınan bağımsız birimlerin emsal bedeli üzerinden KDV hesaplanması gerekmektedir. Arsa sahibinin, gerçek usulde mükellefiyetini gerektirmeyecek şekilde arızi faaliyet olarak arsasını bağımsız birimler karşılığında müteahhide tesliminde ise KDV uygulanmaz."

Tebliğe göre; müteahhit tarafından arsa sahibine yada arsa sahibinin arsa alım satımı konusunda sürekli bir faaliyet göstermesi durumunda emsal bedel üzerinden fatura düzenlenmesi gerekmektedir.

Emsal bedelin tespiti de 213 Sayılı Vergi Usul Kanunu 267. Maddesi 2.sırasındaki maliyet bedeli esasına göre tespit edilmesi gerekmektedir. Emsal bedeli belli edilecek malın, maliyet bedeli bilinir veya çıkarılması mümkün olursa 267/2 maddesine göre tespit edilebilecektir.

\subsection{MÜTEAHHIT'iN INŞAATI DEVAM EDEN DAIRELERIN (TOPRAKTAN SATIŞ) SATIŞLARIN VERGISEL YÖNLERi}

İnşaat devam ederken topraktan yapılan daire satışlarını idare avans olarak değerlendirilmektedir. 3194 sayılı imar kanunu 31. maddesine göre inşaatın bitim tarihi yapı kullanım izin belgesinin alındığı tarihtir. Kullanım belgesi alınmadan önce tasarruf hakkının devri söz konusu ise bu tarih vergi doğuran olaydır.

Uygulama da sıklıkla karşılaşılan bu durum topraktan satış adıyla da tabir edilmektedir. İnşaat faaliyetinde vergiyi doğuran olay inşaatın fiilinden bitmesi, tapu devrinin yapılması yada tasarruf hakkının devri ile gerçekleşmektedir. Yani satış yapılmış olmalı ve işin de bitmiş olması ile vergiyi doğuran olay gerçeklemiş oluyor. Alınan ödemeler 340 ALINAN SiPARiş AVANSLARI hesabında muhasebeleştirilmelidir. (Çatıkkaş \& Şuekinci, 2016:130)

\subsection{ARSA SAHIBINE KONUT TESLIMI VE MALIYET TESPITi}

Müteahhitlerce arsa sahibine daire teslimlerinde en önemli konu KDV matrahının tespitidir. Kat karşılığı inşa edilen birimlerin tesliminde de KDV matrahı, KDV uygulama genel tebliğine göre; "Arsanın bir iktisadi işletmeye dahil olması veya arsa sahibinin arsa alım satımını mutat ve sürekli bir faaliyet olarak sürdürmesi halinde, konut veya işyeri karşılığı müteahhide yapılan bu arsa teslimi KDV'ye tabidir. Ancak arsa sahibinin, gerçek usulde mükellefiyetini gerektirmeyecek şekilde, arızi bir faaliyet olarak arsasını daire veya işyeri karşılığında müteahhide tesliminde vergi uygulanmaz. Müteahhit tarafından arsa sahibine arsanın karşılı̆ı olarak yapılan teslimlerde, emsal bedel üzerinden KDV uygulanır."

VUK 267. maddesinde Maliyet bedeli esası 'na göre; emsal bedeli belli edilecek malın, maliyet bedeli bilinir veya çıkarılması mümkün olursa, bu takdirde mükellef bu maliyet bedeline, toptan satışlar için \% 5, perakende satışlar için \% 10 ilave etmek suretiyle emsal bedelini bizzat belli eder.

Arsa sahibine teslim edilen konutların maliyeti, inşaatın toplam maliyetinin toplam inşaat $\mathrm{m}^{2}$ 'sine bölünmesi ve bulunan değerin arsa sahibine teslim edilen dairelerin toplam $\mathrm{m}^{2}$ sine çarpımı ile maliyet tespiti yapılacaktır.

\section{3. ÖRNEK UYGULAMA}

Arsa Karşıı̆ı inşaat firmaları malzeme alımlarında 150 illk Madde ve Malzeme hesabını kullanmaları gerekmektedir. Malzemeler şantiyede kullanıldıkça 710 Direkt ilık Madde Malzeme hesabına aktarılarak inşaatın malzeme maliyetleri takip edilmektedir. Belediye harcı, proje mühendislik gideri, gibi endirekt giderler de 730 Genel Üretim Gideri hesabında takip edilmektedir.

Aynı anda birden fazla arsa karşılı̆ı faaliyeti yürütülmesi durumunda hesap planında buna uygun bir şekilde revize edilmesi gerekecektir. Örneğin; 361.12 191 Ada 25 Parsel Ödenecek SGK Primleri, 720.12191 Ada 25 Parsel Direk İşçilik Gideri, 361.13 45 Ada 12 Parsel Ödenecek SGK Primleri, 720.1345 Ada 12 Parsel Direk İşçilik Gideri gibi inşaatı ilgilendiren tüm hesaplarda maliyetlerin doğru takip edilebilmesi için detay alt hesaplarda açılması mümkündür. Özellikle 150 ilk Madde Malzeme hesabında malzemelerin inşaatta kullanım sıralamasına bağlı olarak alt hesaplar açılırsa malzeme takibi de çok daha kolay olacaktır. Örneğin; Demir, beton, tuğla gibi sıralama yapılabilir. Ayrıca her firmada müteahhitlik yapamamaktadır. Çevre Şehircilik Bakanlığından müteahhit yetki belgesi numarası alması gerekmektedir.

Örnek; Arsa sahibi Efe Bey ile müteahhit Erda Ltd.Şti. arasında arsa karşılığı inşaat sözleşmesi düzenlenmiştir. Efe Bey'e 1 ve 2'nolu daireleri müteahhit

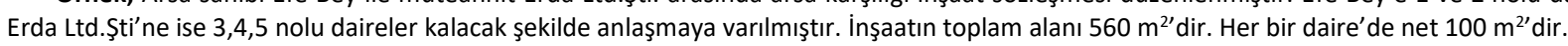

İnşaatın ileriki aşamalarında oluşacak maliyetlerin muhasebe kayıtlarına yer verilememiştir. Çalışmada yer alan örneğimizin beş dairenin inşaat maliyetinin gerçeği yansıtır bir şekilde olması amacıyla ve diğer maliyetlerin gerçekleştiği varsayımıyla inşaatın tamamlandığı düşünülerek oluşan rakamlar aşağıdaki gibi belirlenmiştir.

710.10 Erda apartmanı D.I.M.M Gideri $275.000 \mathrm{TL}$

$\begin{array}{ll}720.10 \text { Erda apartmanı D.Issçilik Gideri } & 45.000 \mathrm{TL}\end{array}$

730.10 Erda apartmanı G.Ü.G $\quad+40.080 \mathrm{TL}$

Arsa Payı Hariç Toplam Üretim Maliyeti $360.080,00 \mathrm{TL}$

\begin{tabular}{lr}
770 Genel Yönetim Gideri & $10.080 \mathrm{TL}$ \\
\hline
\end{tabular}

Çözüm: Arsa payı hariç birim $\mathrm{m}^{2}$ maliyeti $=360.080,00 \mathrm{TL} / 560 \mathrm{~m}^{2}=643 \mathrm{TL} / \mathrm{m}^{2}$

1 adet daire maliyeti $=100 \mathrm{~m}^{2} \times 643,00 \mathrm{TL} / \mathrm{m}^{2}=64.300,00 \mathrm{TL}-$ (Arsa payı hariç)

Giderlerin maliyete yansıtılması

\begin{tabular}{lr}
\hline 711.10 Erda apartmanı D.I.M.M Gideri & $275.000 \mathrm{TL}$ \\
721.10 Erda apartmanı D.İşçilik Gideri & $45.000 \mathrm{TL}$ \\
731.10 Erda apartmanı G.Ü.G & $40.080 \mathrm{TL}$
\end{tabular}

710.10 Erda apartmanı D.I.M.M Gideri

720.10 Erda apartmanı D.İşçilik Gideri $\quad$ 45.000 TL

730.10 Erda apartmanı G.Ü.G 40.080 TL

151.10 Erda apartmanı Yarı mamuller $360.080 \mathrm{TL}$

711.10 Erda apartmanı D.I.M.M Gideri $\quad 275.000$ TL

721.10 Erda apartmanı D.İşçilik Gideri $\quad$ 45.000 TL

731.10 Erda apartmanı G.Ü.G 40.080 TL 
$200 \mathrm{~m}^{2}$ arsa sahibine kalan her biri $100 \mathrm{~m}^{2}$ olan 1 ve 2 nolu dairelerin $\mathrm{m}^{2}$ lerinin toplamı'dır.

KDV kanunu 27/4 maddesi gereği GYG 'den emsal bedel tespit edildiği için pay verilmesi gerekir. Buda şu şekilde hesaplanır.

$1 \mathrm{~m}^{2}$ ye düşen GYG hissesi = Dönem GYG / Toplam üretim $\left(\mathrm{m}^{2}\right)$

$10.080 \mathrm{TL} / 560 \mathrm{~m}^{2}=18,00 \mathrm{TL} / \mathrm{m}^{2}$

Arsa sahibine verilen birimlere düşen KDVK 27/4 gereği GYG hissesi $=200 \mathrm{~m}^{2} * 18 \mathrm{TL} / \mathrm{m}^{2}=3.600 \mathrm{TL}$

KDV matrahının hesabı:

128.600 TL

KDVK Mad. 27/4 Mamule Düşen G.Y.Gid. hissesi $3.600 \mathrm{TL}$

$132.200 \mathrm{TL}$

VUK 'nun 267.Mad.gereği \%5 ilave

$6.610 \mathrm{TL}$

K D V MATRAHI

$138.810,00 \mathrm{TL}$

KDV \% 1

$1.388,10 \mathrm{TL}$

FATURA TOPLAMI

$140.198,10 \mathrm{TL}$

Yevmiye Kaydı;

710.10.005 Erda apartmanı arsa maliyeti 138.810 TL

320.10.001 Arsa sahipleri

$138.810 \mathrm{TL}$

Arsanın üretim maliyetine alınması

$$
1
$$

VUK 271.maddesi inşa ve imal giderlerinin satın alma bedeli yerine geçeceği hükmüne göre; müteahhit firmanın inşa ve imal giderlerinden hesaplayarak arsa sahibine kestiği bedel müteahhit için arsayı satın alma bedeli yerine geçeceğinden arsa üretim maliyetine alınmıştır. Bu muhasebe kaydını yaparken müteahhit tarafından da gider pusulası düzenlenmesi gerekmektedir.

1

120.10.001 Arsa sahipleri

140.198,10 TL
600 Yurt içi satışlar
138.810,00 TL
391.01.001 Hesaplanan KDV
1.388,10 TL

Arsa sahibine dairelerin teslimi

$\begin{array}{ll}138.810 \mathrm{TL} & \\ \text { 320.10.001 Arsa Sahipleri } & 120.10 .001 \text { Arsa sahipleri } \\ & 138.810 \mathrm{TL}\end{array}$

(Arsa sahipleri hesabının kapatılması amacıyla yapılması gereken muhasebe kaydıdır. Gerçekte arsa sahibi bizim için müşteri veya satıcı değildir.)

$\begin{array}{ll}151.10 \text { Erda apartmanı Yarı mamuller } & 138.810 \mathrm{TL} \\ 711.10 .005 \text { Erda apartmanı } & \text { arsa maliyeti yansıtma hesabı }\end{array}$

711.10.005 Erda apartmanı arsa maliyeti yansıtma hesabı

$138.810 \mathrm{TL}$

710.10.005 Erda apartmanı arsa maliyeti $138.810 \mathrm{TL}$

152 Mamuller Hesabı

498.890 TL

151.10 Erda apartmanı yarı mamuller $498.890 \mathrm{TL}$

Tamamlanan inşaatın mamuller hesabına devri

\begin{tabular}{ll}
\hline 620 Satılan mamul maliyeti & $138.810 \mathrm{TL}$ \\
Arsa sahibi daireleri & 152 Mamuller
\end{tabular}

Arsa sahibine kesilen faturada en önemli sorun KDV matrahının tahsilidir. 


\section{SONUÇ}

İnşaat muhasebesinde yapılan faaliyetin özel inşaat faaliyeti mi yoksa taahhüt işi mi olduğu konusu doğru tespit edilmesi en önemli konudur. Çünkü, özel inşaat yada kat karşılığı inşaat faaliyetini taahhüt işi gibi muhasebeleştirdiğinizde ya da tam tersi durumda ciddi anlamda vergi ziyaına sebebiyet verilmiş olacaktır. Ayrıca arsa sahibi ile müteahhit arasındaki gayri nakdi bedel ödemesi söz konusu olduğundan ve gelir idaresi yapılan işlemi trampa olarak değerlendirdiğinden arsa sahibine fatura düzenlenmesi ya da arsa sahibinin gelirinin tespiti ciddi karışılıklara sebebiyet vermektedir. Örneğin arsa sahibine faturanın düzenlenme zamanı Gelir İdaresine göre eşanlı olarak teslim veya iskan tarihinden hangisi önce ise o tarihte düzenlenmelidir. Bu tarihin atlandığı ve üzerinden de bir hesap dönemi geçtiğini düşündüğümüzde fatura tutarı da müteahhidin e-defter kullanıcı olmasına sebebiyet verecek kadar yüksek bir tutar ise hakikaten faturanın doğru zamanda ve doğru tutarda düzenlenmesi hayati öneme sahiptir. Çalışmada arsa karşılığı inşaat işleri ile ilgili özellikli bir konu olan arsa sahibine fatura düzenlenmesi örnek yardımıyla açıklanmıştır. Bundan sonraki çalışmalarda arsa karşılığı inşaat faaliyetinin vergisel yönleri ile ele alınacağı gibi literatürde şimdiye kadar hiç çalışılmamış olan Türkiye Finansal Raporlama Standartlarına göre de konunun çalışılmasının akademik anlamda literatüre katkısı olacağı düşünülmektedir.

\section{KAYNAKÇA}

Çatıkkaş Özgür, Şuekinci Cafer , (2013) "TMS-11 inşaat sözleşmeleri standardına göre inşaat muhasebesi ve vergi uygulamaları" Hesap Uzmanları Derneği, İstanbul

Çatıkkaş,Ö., Şuekinci,C., (2016) “Kat karşıı̆ı̆ı inşaat muhasebesi ve vergi uygulamaları” , Hesap Uzmanları Derneği, İstanbul

Çatıkkaş,Ö., Şuekinci,C.,(2012), “Özel inşaat(yap-sat) işletmelerinin vergisel yönleriyle incelenmesi ve muhasebe uygulamaları "Vergi dünyası dergisi,

(368), 171-179

Çatıkkaş, Ö., Esen, Ö., \& Şuekinci, C. (2018). Büyük ve orta boy işletmeler için finansal raporlama standardı (BOBi FRS) ve yıllara yaygın inşaat muhasebesi uygulama örneği. Sayıştay Dergisi, (108), 191-209.

Demir,E. (2015), "Yıllara yaygın inşaat, taahhut ve onarım işlemlerinde vergilendirme ve muhasebeleştirme esasları uzerine bir değerlendirme", Uluslararası Sosyal Araştırmalar Dergisi,8(36), 834-845

Örten, R., Kaval, H., Karapınar, A.(2015) “Türkiye muhasebe- finansal raporlama standartları uygulama ve yorumları” ,Gazi Kitabevi, Ankara

ÖZCAN, Zekai, Kat karşılığı inşaat işinde arsa sahibine kalan dairelerin satışından elde edilen kazancın vergilendirilmesi, Lebib Yalkın Mevzuat Dergisi,

Sayı 96, Aralık 2011.

Selimoğlu,R.,(2013) “İnşaat muhasebesi ve vergi uygulamaları",Hipotez Yayınları, İzmir

Türüt Ş., Vergisel ve hukuki boyutlarıyla kat karşılığı inşaat işleri, Yaklaşım Yayıncılık, Ankara 2009, s.218

Yereli, A. N., Kayalı N., Demirlioğlu L. (2011), “Inşaat sözleşmelerine ilişkin Türkiye Muhasebe Standardı (TMS 11) çerçevesinde yıllara yaygın inşaat taahhüt işlerinin muhasebeleştirilmesi”, Dokuz Eylül Üniversitesi Sosyal Bilimler Enstitüsü Dergisi ,13(3),113-135

193 Sayılı Gelir Vergisi Kanunu

213 Sayılı Vergi Usul Kanunu

3194 Sayılı İmar Kanunu

KDV Uygulama Genel Tebliği 